\title{
Assessing the impact of a shadowing programme on in-hospital mortality following trainee doctors' changeover
}

Balinskaite Violeta*, Bottle Alex and Aylin Paul

\begin{abstract}
Background: To assess the impact on seven-day in-hospital mortality following the introduction in 2012 of a shadowing programme for new UK medical graduates requiring them to observe the doctor they are replacing for at least 4 days before starting work.

Methods: Data on emergency admissions were derived from Hospital Episode Statistics between 2003 and 2019. A generalised estimating equation model was used to examine whether the introduction of the programme was associated with a change in mortality.

Results: There were 644,018 emergency admissions, of which 1.8\% (7612) ended in death in hospital within a week following the admission. Throughout the study period, there was an annual increase in the number of emergency admissions during July and August, though in-hospital mortality rates declined. The generalised estimating equation analysis found no significant change in the odds of death within 7 days after admission for patients admitted on the first Wednesday in August compared with patients admitted on the last Wednesday in July $(\mathrm{OR}=$ $1.03,95 \% \mathrm{Cl} 0.94-1.13, p=0.53)$. Furthermore, there was no significant change observed for any clinical diagnosis category following the introduction of the shadowing programme.

Conclusion: There was a rising trend in the number of emergency admissions over the study period, though mortality was decreasing. We found no significant association between the introduction of shadowing programme and in-hospital mortality; however, lack of power means that we cannot rule out a small effect on mortality. There are other outcomes that might have changed but were not examined in this study.
\end{abstract}

Keywords: In-hospital mortality, Trainee doctors' changeover, Programme evaluation

\section{Introduction}

In the United Kingdom, newly qualified doctors begin their residency training on the first Wednesday in August and has been grimly referred to as "Black Wednesday", while in North America it happens in July and is known as the "July Phenomenon" $[1,2]$. Interest in the potential adverse effects on patient care during this changeover attracted a significant amount of research in the United States [3]. In England, only three studies

* Correspondence: v.balinskaite@imperial.ac.uk

School of Public Health, Imperial College London, London, AZ SW7, UK investigated the association between changeover and adverse patient outcomes, and mixed results were found [4-6]. In early work, Aylin et al. found no significant change in mortality but were only able to examine numbers of death registrations rather than hospital mortality rates [4]. Shuhaiber and colleagues looked at the effect of cardiothoracic resident turnover on cardiac surgical outcomes and found a 30\% higher odds of in-hospital mortality after a complex cardiac operation [5]. A later study using administrative hospital data found evidence that patients admitted on the first Wednesday in August

C C The Author(s). 2021 Open Access This article is licensed under a Creative Commons Attribution 4.0 International License, which permits use, sharing, adaptation, distribution and reproduction in any medium or format, as long as you give appropriate credit to the original author(s) and the source, provide a link to the Creative Commons licence, and indicate if changes were made. The images or other third party material in this article are included in the article's Creative Commons. licence, unless indicated otherwise in a credit line to the material. If material is not included in the article's Creative Commons licence and your intended use is not permitted by statutory regulation or exceeds the permitted use, you will need to obtain permission directly from the copyright holder. To view a copy of this licence, visit http://creativecommons.org/licenses/by/4.0/ The Creative Commons Public Domain Dedication waiver (http://creativecommons.org/publicdomain/zero/1.0/) applies to the data made available in this article, unless otherwise stated in a credit line to the data. 
had a higher risk of early death compared with patients admitted on the last Wednesday in July [6]. Furthermore, higher mortality risk was observed for patients admitted with a primary medical (rather than surgical or cancer) diagnosis. As a direct consequence of the latter study, in 2012 the Medical Director of the National Health Service (NHS) introduced a shadowing programme. The aim of the programme was to ensure that those entering the foundation year 1 doctor (FY1) posts gain practical familiarity with the specific clinical environment they will be working in [7-9]. The expectation was that such experience directly improves patient safety and benefits the wider functioning of the team, allowing other staff to be included while ensuring adequate staffing of wards and clinics. Though the shadowing programme was compulsory, there was no national curriculum, although guidance was provided to hospital trusts for the induction period (at least 4 days of the induction) [10]. Due to the latter, the form of the inductions carried out varied between trusts: from 4 days to a 2-week programme.

In this follow-up study, we aimed to investigate whether the introduction of the shadowing programme intervention was associated with a change in the inhospital mortality for patients admitted on the day of the changeover (first Wednesday in August) compared with patients admitted on the previous Wednesday in July using the same methodology as our previous study [6].

\section{Methods}

Patient-level data was extracted from Hospital Episode Statistics (HES) between 2003 and 2019. It is an administrative database that contains information on all admissions to English NHS hospital trusts (trusts can comprise multiple hospital sites). Each patient record contains demographic information (e.g. age, sex and socioeconomic deprivation), the episode of care (for example, date of admission) and diagnosis. Diagnoses are recorded using the International Classification of Diseases, 10th edition (ICD-10). Each patient episode was linked into 'spells' (admissions to one provider) and spells were linked into 'superspells' (which combine any interhospital transfers). Two patient cohorts were identified: emergency patients admitted on the last Wednesday in July (used as controls) and emergency patients admitted on the first Wednesday in August. We included only acute trusts (168 trusts) that each year take on trainee doctors on the first Wednesday in August. All admissions were divided into three clinical categories based on the Agency for Healthcare Research and Quality's 259 Clinical Classification System (CCS) diagnostic groups: medical, surgical and neoplasm.
The outcome of interest was all-cause seven-day inhospital mortality in patients admitted on the first Wednesday in August (changeover group) compared with patients admitted on the last Wednesday in July (control group).

Descriptive data were summarised as total numbers and percentages, grouped by the day of admission and pre/post-shadowing programme (intervention). The crude and adjusted odds ratios and their $95 \%$ confidence intervals before and after the shadowing programme were estimated using multilevel logistic regression [11]. The following patient-level variables were included in the regression model: age (six-year bands: $0-14,15-44$, $45-64,65-74,75-84,85+)$, gender, small-area socioeconomic deprivation (Carstairs quintile) [12], Charlson score (co-morbidities score, NHS adaptation) [13], year and week of admission.

A generalised estimating equation (GEE) with autoregressive correlation structure model was used to examine how in-hospital mortality changed over time and how it was affected by the introduction of the shadowing programme $[14,15]$. The model included binary variables for group ( 1 - if patient was admitted on the last Wednesday in July (control group), 0 - if patient was admitted on the first Wednesday in August (changeover group)) and intervention (1 - after shadowing programme, 0 - before shadowing programme), fixed effects for time, and random trust-level effects to adjust for the dependency of observations within each trust. In addition, the model was adjusted by patient-level variables such as age, gender, small-area socioeconomic deprivation, Charlson comorbidity score, year and week of admission. A $p$-value less than 0.05 was considered statistically significant, and all analysis was carried out with SAS 9.4 software package (SAS Institute, Cary, N.C., USA).

\section{Ethical considerations}

Ethical approval was obtained from the London-South East Ethics Committee (REC ref. 15/LO/0824) to use data for research and measuring quality of delivery of healthcare.

\section{Results}

During the study period, 644,018 emergency admissions were extracted $(325,307$ occurred on the last Wednesday in July and 318,711 occurred on the first Wednesday in August). Over 1.2\% (7612) of these admissions ended in death in hospital within a week following the admission Table S1 (see Additional file 1). Throughout the study period, there was a steady increase in emergency admissions during July and August, though in-hospital mortality rates declined (Figs. 1 and 2). There was a small difference in the characteristics of patients admitted on 


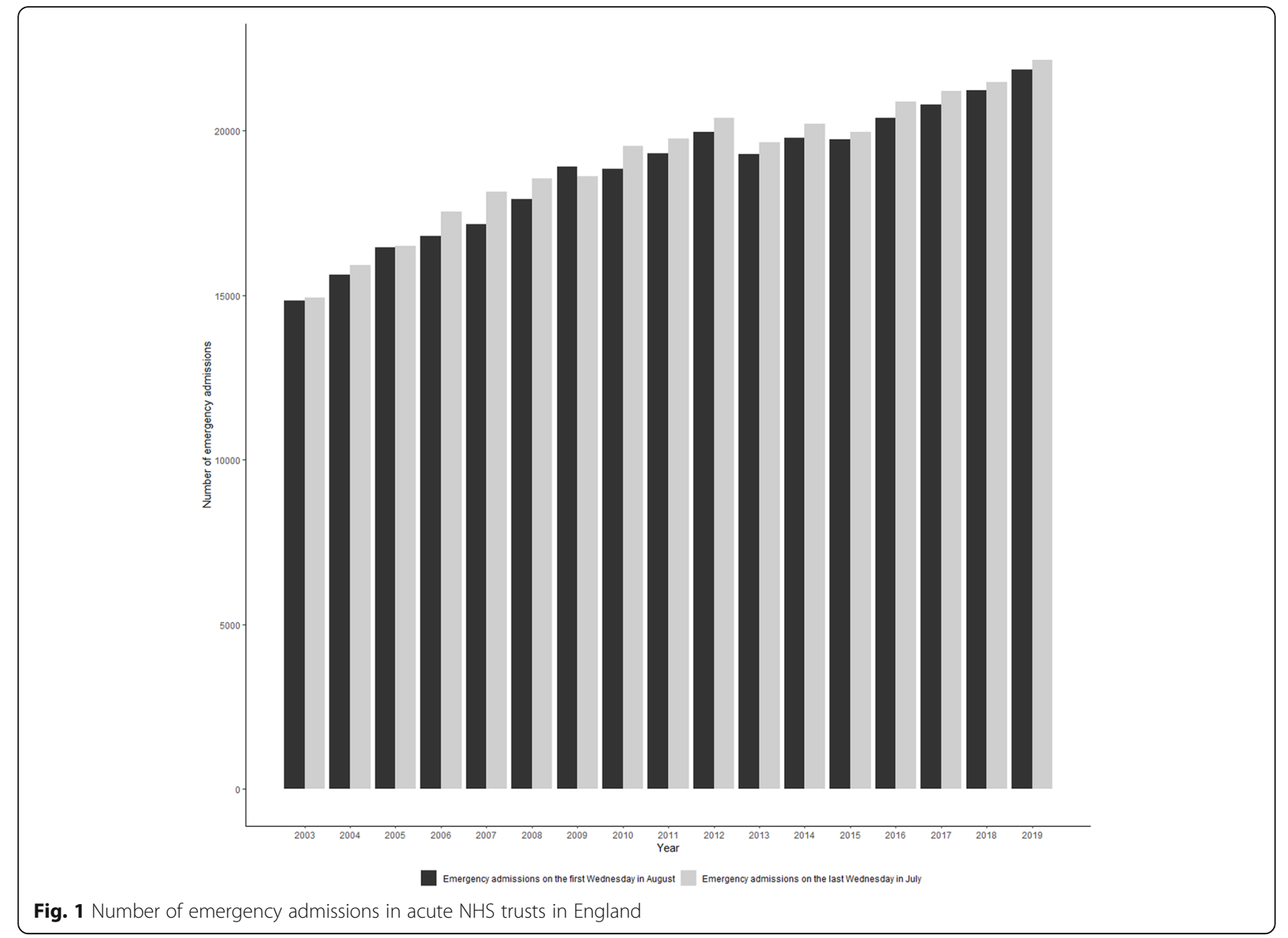

the last Wednesday in July compared with patients admitted on the first Wednesday in August. However, comparing patient characteristics before (2003 to 2011) and after (2012 to 2019) the shadowing programme was implemented, there was a higher proportion of older and comorbid patients admitted to hospital after the intervention. There was no significant difference in unadjusted seven-day in-hospital mortality rates $(1.2 \%$ vs $1.2 \%, p=0.47)$. No significant differences in unadjusted mortality rates were observed for any clinical diagnosis category (medical: $1.5 \%$ vs $1.4 \%, p=0.52$; surgical: $0.4 \%$ vs $0.4 \%, p=0.60$; and neoplasm: $6.0 \%$ vs $5.5 \%, p=0.39$ ).

The simple pre-post intervention analysis showed that the implementation of the shadowing programme had no significant impact on seven-day in-hospital mortality (Table 1). After adjustment for age, gender, comorbidities, small-area socioeconomic deprivation and year, there was no significant change in the odds ratio of death for the changeover vs control pre-intervention $(\mathrm{OR}=1.03,95 \% \mathrm{CI} 0.97$ to $1.09, p=0.33)$ compared with post-intervention $(\mathrm{OR}=1.06,95 \% \mathrm{CI} 0.98$ to $1.14, p=$ 0.11). During the same period, there was no significant change for each clinical diagnosis category.
Table 2 and Table S2 (see Additional file 1) present the results of the generalised estimating equation model. For patients admitted on the first Wednesday in August, there was no significantly higher odds of death within 7 days after admission compared with patients admitted on the last Wednesday in July (OR $=1.03,95 \%$ CI $0.94-$ $1.13, p=0.53)$. Furthermore, there was no significant change observed for any clinical diagnosis category.

\section{Discussion}

In this observational study, we aimed to evaluate the association between the introduction of a national shadowing programme and in-hospital mortality during the first Wednesday in August. During the study period, the number of emergency admissions was increasing over time, though the mortality rates were declining. We found no significantly higher odds of death in mortality for patients admitted on the first Wednesday in August compared with patients admitted on the last Wednesday in July. Furthermore, we did not observe a significant change in either the medical, surgical or neoplasm diagnosis groups. 

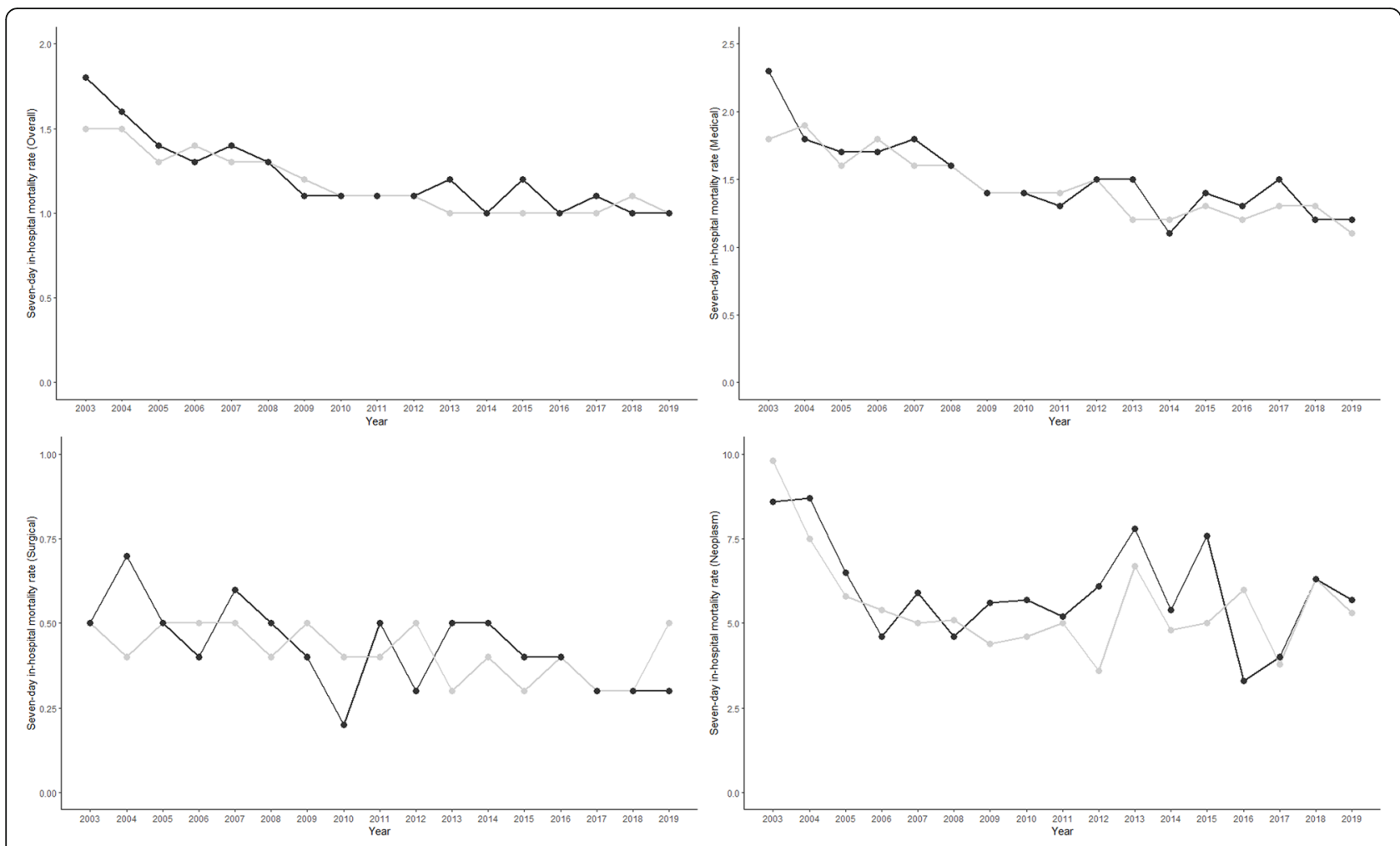

Fig. 2 Crude in-hospital mortality rates in England between 2003 and 2019

\section{Comparison with other studies}

This is the first study that has assessed the impact of a shadowing programme on patient outcomes in healthcare though the evaluation of satisfaction of trainees was performed [16]. The programme is designed for final year medical students to observe an existing doctor undertaking the usual activities required of their role for 4 days before starting work. Only a few previous studies investigated the impact of the various induction programmes for junior doctors; however, all these studies reported only perceived benefits rather than changes in patient outcomes [17].

A significant amount of research investigated the association between the beginning of newly qualified doctors training and adverse effects on patient care [3]. The majority of these studies focused on 30-day or overall mortality for various subgroups of the patient [3, 18-20] or patients admitted to the intensive care unit $[3,21]$. Only around $20 \%$ of these studies found an increase in mortality during the changeover, with an increase in relative risk between 4.3 and $41 \%$ or an adjusted odds ratio of 1.08 to 1.34 .

Only two studies in the UK investigated the relationship between changeover and in-hospital mortality. Shuhaiber and colleagues [5] investigated the effect of cardiothoracic resident turnover on cardiac surgical outcomes and found a 30\% higher odds of in-hospital mortality after a complex cardiac operation, but not for CABG alone. Jen et al. [6] found a $6 \%(\mathrm{OR}=1.06,95 \% \mathrm{CI} 1.00$ to 1.13$)$ higher mortality for patients admitted on the first Wednesday in August compared with patients on the last Wednesday in July [6]. Furthermore, they found a significant increase in mortality for medical patients $(\mathrm{OR}=1.08,95 \% \mathrm{CI} 1.01$ to $1.16, p=0.03$ ) but not for surgical or cancer patients. In comparison with Jen et al's study, we found similar results for the pre-intervention period for all patients (1.03 vs. 1.06). However, in this study we looked at different time periods (Jen looked at 2000-8, and we looked at 200311). Interestingly, in our study, we found no significant increase in mortality for medical patients. In both studies, CCS diagnostic groups were used to divide admissions into three clinical categories; however, the proportions of medical and surgical diagnostic groups in our study $(61.6$ and $36.0 \%)$ were different from the one in Jen et al. work (85.1 and $12.1 \%)$. The reason why these proportions are different is not clear, but we were unable to replicate the groups exactly, which may explain different results.

\section{Strengths and limitations of the study}

The main strength of our study is the use of a large and rich national administrative dataset that contains all hospital admissions and information relating to patient 
Table 1 Unadjusted/adjusted odds ratios and 95\% confidence intervals before and after the implementation of the shadowing programme

\begin{tabular}{|c|c|c|c|c|}
\hline \multirow[t]{2}{*}{ Models } & \multicolumn{2}{|l|}{2003 to 2011} & \multicolumn{2}{|l|}{2012 to 2019} \\
\hline & Odds ratio $(95 \% \mathrm{Cl})$ & $P$ value & Odds ratio $(95 \% \mathrm{Cl})$ & $P$ value \\
\hline \multicolumn{5}{|l|}{ All diagnosis } \\
\hline No covariates included & $1.03(0.97$ to 1.10$)$ & 0.30 & 1.05 (0.98 to 1.12$)$ & 0.20 \\
\hline All covariates included & $1.03(0.97$ to 1.09$)$ & 0.33 & $1.06(0.98$ to 1.14$)$ & 0.11 \\
\hline \multicolumn{5}{|c|}{ Reallocated by primary diagnosis } \\
\hline \multicolumn{5}{|l|}{ Medical } \\
\hline No covariates included & $1.02(0.96$ to 1.10$)$ & 0.47 & $1.05(0.97$ to 1.14$)$ & 0.22 \\
\hline All covariates included & $1.02(0.95$ to 1.09$)$ & 0.59 & $1.06(0.97$ to 1.15$)$ & 0.18 \\
\hline \multicolumn{5}{|l|}{ Surgical } \\
\hline No covariates included & $1.07(0.91$ to 1.25$)$ & 0.41 & 0.99 (0.83 to 1.18$)$ & 0.93 \\
\hline All covariates included & $1.06(0.90$ to 1.25$)$ & 0.47 & $1.02(0.86$ to 1.21$)$ & 0.84 \\
\hline \multicolumn{5}{|l|}{ Neoplasm } \\
\hline No covariates included & $1.07(0.90$ to 1.26$)$ & 0.44 & $1.11(0.93$ to 1.32$)$ & 0.24 \\
\hline All covariates included & 1.08 (0.91 to 1.27$)$ & 0.40 & 1.12 (0.94 to 1.33$)$ & 0.20 \\
\hline
\end{tabular}

Table 2 Results of generalised estimating equation analysis (odds ratio and its 95\% confidence intervals) of seven-day in-hospital mortality between patients admitted to hospital on the first Wednesday in August compared with patients admitted on the last Wednesday in July

\begin{tabular}{|c|c|c|}
\hline Outcome & OR $(95 \% \mathrm{Cl})$ & $p$-value \\
\hline \multicolumn{3}{|l|}{ Overall } \\
\hline Time & $0.93(0.92-0.94)$ & $<0.0001$ \\
\hline Group (changeover group vs control group) & $1.03(0.97-1.09)$ & 0.33 \\
\hline Intervention (after intervention vs before intervention) & $1.04(0.95-1.15)$ & 0.39 \\
\hline Group*Intervention & $1.03(0.94-1.13)$ & 0.53 \\
\hline \multicolumn{3}{|l|}{ Reallocated by primary diagnosis } \\
\hline \multicolumn{3}{|l|}{ Medical } \\
\hline Time & $0.93(0.92-0.95)$ & $<0.0001$ \\
\hline Group (changeover group vs control group) & $1.02(0.95-1.09)$ & 0.60 \\
\hline Intervention (after intervention vs before intervention) & $1.01(0.90-1.14)$ & 0.84 \\
\hline Group*Intervention & $1.04(0.93-1.17)$ & 0.48 \\
\hline \multicolumn{3}{|l|}{ Surgical } \\
\hline Time & $0.94(0.91-0.96)$ & $<0.0001$ \\
\hline Group (changeover group vs control group) & $1.06(0.90-1.25)$ & 0.47 \\
\hline Intervention (after intervention vs before intervention) & $0.99(0.73-1.33)$ & 0.93 \\
\hline Group*Intervention & $0.96(0.78-1.20)$ & 0.96 \\
\hline \multicolumn{3}{|l|}{ Neoplasm } \\
\hline Time & $0.93(0.90-0.96)$ & $<0.0001$ \\
\hline Group (changeover group vs control group) & $1.08(0.91-1.28)$ & 0.38 \\
\hline Intervention (after intervention vs before intervention) & $1.45(1.06-1.96)$ & 0.02 \\
\hline Group*Intervention & $1.04(0.82-1.33)$ & 0.75 \\
\hline
\end{tabular}


characteristics and some key outcomes such as inhospital death. However, given that we focused on only 2 days of admissions a year and included only 7-day outcomes (to eliminate any potential overlap of care), we lacked power to detect small differences.

Another strength is the use of the generalised estimating equation method. The advantage of GEE models is that it provides unbiased estimation of population-level estimates despite the possible misspecification of the correlation structure. Furthermore, the use of GEE models with a control group enabled us to examine the effect of the shadowing programme despite the overall reduction in mortality in England (Fig. 2). The latter could make simple pre-post analysis potentially misleading.

Limitations mainly concern data availability. It is likely that a number of factors are responsible for the fall in in-hospital mortality over time, from changes in team mix and ways of working to discharge policies. For instance, there has been much work on failure to rescue following surgical complications [22], and teamwork is known to be important. Patient mix can change over time and can affect intervention effects if there is unmeasured confounding. Although the national hospital dataset includes information related to patient characteristics and the episode of care, ICD-10 is poor at capturing the severity of the disease. This could differ between the two patient groups, but its impact is likely to be modest. Furthermore, the dataset does not include any information related to intra-hospital transfers, which have been linked to various adverse outcomes, [22] or interpersonal and organisational dynamics within hospitals [23]. The programme may also have had an impact on other patient outcomes and have had educational benefits for staff that we could not assess.

Another potential factor that we were not able to account for was the emotional preparation of junior doctors. It has been shown that the start of a job in a new hospital can be a stressful time for junior doctors, which may affect the number of errors they make [24]. Moreover, every new medical member of staff has to attend organisational induction and mandatory training, which requires many doctors to be absent from patient care for a significant period [25].

\section{Conclusions}

During the study period, we found no significant association between the introduction of shadowing programme and in-hospital mortality after adjusting for the preexisting downward trend in mortality and available casemix factors; however, methodological limitations limit the power of the study and we cannot rule out an effect of the shadowing programme on other outcomes.

\section{Supplementary Information}

The online version contains supplementary material available at https://doi. org/10.1186/s12913-021-06578-y.

\section{Additional file 1.}

Acknowledgements

This work uses data provided by patients and collected by the NHS as part of their care and support.

\section{Authors' contributions}

$P A, A B$ and $V B$ contributed to the original research proposal. PA was instrumental in securing the data. VB carried out the analysis and wrote the first draft. VB, PA and $A B$ read and approved the final manuscript.

\section{Funding}

The Dr. Foster Unit is an academic unit in the Department of Primary Care and Public Health, within the School of Public Health, Imperial College London. The unit receives research funding from the National Institute of Health Research and Dr. Foster Intelligence, and independent health service research organisation (a wholly owned subsidiary of Telstra). The Dr. Foster Unit at Imperial is affiliated with the National Institute of Health Research (NIHR) Imperial Patient Safety Translational Research Centre. The NIHR Imperial Safety Translational Centre is a partnership between the Imperial College Healthcare NHS Trust and Imperial College London. The Department of Primary Care \& Public Health at Imperial College London is grateful for support from the NW London NIHR Applied Research Collaboration and the Imperial NIHR Biomedical Research Centre. The views expressed in this publication are those of the authors and not necessarily those of the National Health Service (NHS), the NIHR or the Department of Health and Social Care.

\section{Availability of data and materials}

The data that support the findings of this study are available from NHS DIGI TAL in England but restrictions apply to the availability of these data, which were used under agreement between NHS DIGITAL and Dr. Foster Unit at Imperial, and so are not publicly available. The authors are not in a position to release the data (in accordance with the agreement with NHS DIGITAL). The data can be access via NHS Digital, all information who can access data and how to apply for the access can be found here: https://digital.nhs.uk/ data-and-information/data-tools-and-services/data-services/hospital-episodestatistics/users-uses-and-access-to-hospital-episode-statistics

\section{Declarations}

\section{Ethics approval and consent to participate}

The principal investigator has approval from the Secretary of State and the Health Research Authority under Regulation 5 of the Health Service (control of Patient Information) Regulations 2002 to hold confidential data and analyse them for research purposes (CAG ref. 15/CAG/0005). We have approval to use them for research and measuring quality of delivery of healthcare, from the London-South East Ethics Committee (REC ref. 15/LO/ 0824). This allows approved researchers to securely access de-identified data for research purposes, without seeking individual's consent.

\section{Consent for publication}

Not applicable.

\section{Competing interests}

None declared.

Received: 17 February 2021 Accepted: 24 May 2021

Published online: 07 June 2021

\section{References}

1. Hughes E. July effect? Maybe not. Can Med Assoc J. 2017;189(32):E1050-1.

2. Innes E. Black Wednesday: today junior doctors will start work and cause A\&E death rates to increase by SIX per cent. Daily Mail. 2013 https://www. dailymail.co.uk/health/article-2385931/Black-Wednesday-Today-juniordoctors-start-work-causing-A-E-death-rates-6.html. Accessed 10 July 2019. 
3. Young JQ, Ranji SR, Wachter RM, et al. "July effect": impact of the academic year-end changeover on patient outcomes: a systematic review. Ann Intern Med. 2011;155(5):309-15.

4. Aylin P, Majeed FA. The killing season - fact or fiction? The BMJ. 1994; 309(6970):1690.

5. Shuhaiber JH, Goldsmith K, Nashef K. Impact of cardiothoracic resident turnover on mortality after cardiac surgery: a dynamic human factor. Ann Thorac Surg. 2008:86:123-31.

6. Jen MH, Bottle A, Majeed A, et al. Early in-hospital mortality following trainee doctors' first day at work. PLoS One. 2009;4(9):e7103.

7. Department of Health and Social Care. Lives will be saved as junior doctors shadow new role. 2012. https://www.gov.uk/government/news/lives-will-besaved-as-junior-doctors-shadow-new-role. Accessed 10 July 2019

8. Academy of Medical Royal Colleges, NHS Employers. Recommendations for safe trainee changeover. $2013 \mathrm{http}: / /$ www.aomrc.org.uk/wp-content/uploa ds/2016/05/Recommendations_for_Safe_Trainee_Changeover_0613.pdf. Accessed 10 July 2019

9. British Medical Association. Shadowing for final year medical students. 2017. https://www.bma.org.uk/advice/employment/contracts/juniors-contracts/ induction-and-shadowing/shadowing. Accessed 10 July 2019.

10. Sukcharoen K, Everson M. A novel approach to junior doctor induction: a near-peer based curriculum developed and delivered by outgoing foundation year doctors. BMJ Qual Improv Rep. 2014;3:U203556.w1603.

11. Hox JJ, Moerbeek M, Van de Schoot R. Multilevel analysis: techniques and applications: Routledge; 2017.

12. Carstairs V, Morris R. Deprivation and health in Scotland. Health Bull (Edinb). 1990;48(4):162-75.

13. Bottle A, Aylin P. Comorbidities scores for administrative data benefited from adaptation local coding and diagnostic practices. J Clin Epidemiol. 2011;64(12):1426-33.

14. Twisk JW. Applied longitudinal data analysis for epidemiology: a practical guide: Cambridge University Press; 2013.

15. Hanley JA, Negassa A. deB Edwardes MD, Forrester JE. Statistical analysis of correlated data using generalized equations: an orientation. Am J Epidemiol. 2003;157(4):364-75.

16. Health Education England. Shadowing for appointees to foundation year 1 guidance notes. 2014. https://www.nwpgmd.nhs.uk/sites/default/files/ HEE\%20Shadowing\%20Guidance\%202014_0.pdf. Accessed 11 Jan 2021.

17. McMenamin L, Blencowe N, Roland D. Are educational or quality improvement interventions delivered at the induction or orientation of junior doctors effective? J Hosp Admin. 2014;3(5):14-9.

18. Anderson KL, Koval KJ, Spratt KF. Hip fracture outcome: is there a "July effect"? Am J Orthop (Belle Mead, N.J.). 2009;38(12):606-11.

19. Englesbe MJ, Fan Z, Baser O, Birkmeyer JD. Mortality in medicare patients undergoing surgery in July in teaching hospitals. Ann Surg. 2009;249(6): 871-6.

20. Smith ER, Butler WE, Barker FG 2nd. Is the a "July phenomenon" in pediatric neurosurgery at teaching hospitals? J Neurosurg. 2006;105:169-76.

21. Barry WA, Rosethal GE. Is the July phenomenon? The effect of July admission on intensive care mortality and LOS in teaching hospitals. J Gen Med Med. 2003;18(8):639-45.

22. Smith ME, Wells EE, Friese CR, Krein SL, Ghaferi AA. Interpersonal and organizational dynamics are key drivers of failure to rescue. Health Aff. 2018; 37(11):1870-6.

23. Bristol AA, Schneider CE, Lin S, Brody AA. A systematic review of clinical outcomes associated with intrahospital transitions. J Healthc Qual. 2020; 42(4):175-87.

24. Houston DM, Allt SK. Psychological distress and error making among junior house officers. Br J Health Psychol. 1997:2(2):141-51.

25. Gaskell N, Hinton R, Page T, Elvins T, Malin A. Putting an end to black wednesday: improving patient safety by achieving comprehensive trust induction and mandatory training by day 1. Clin Med J. 2016;16(2):124-8.

\section{Publisher's Note}

Springer Nature remains neutral with regard to jurisdictional claims in published maps and institutional affiliations.

\section{Ready to submit your research? Choose BMC and benefit from:}

- fast, convenient online submission

- thorough peer review by experienced researchers in your field

- rapid publication on acceptance

- support for research data, including large and complex data types

- gold Open Access which fosters wider collaboration and increased citations

- maximum visibility for your research: over $100 \mathrm{M}$ website views per year

At $\mathrm{BMC}$, research is always in progress.

Learn more biomedcentral.com/submissions 